\title{
Comparison and Correlation of Cytology, Colposcopy and Histopathology of Premalignant Lesions of Cervix In Rural Women of Barabanki District
}

\author{
Dr.Shashwat Vidyadhar ${ }^{1 *}$, Dr.Aarti B.Bhattacharya ${ }^{2}$, Dr.Sangita Bohara ${ }^{3}$, \\ Dr.A.D. Dwivedi ${ }^{4}$, Dr.Anjana Agarwal ${ }^{5}$, Dr.Deepti Gangwar ${ }^{6}$ \\ ${ }^{1}$ Post-Graduate Resident, Department of Pathology, Hind Institute of Medical Sciences, Barabanki, U.P. \\ ${ }^{2}$ Professor, Department of Pathology, Hind Institute of Medical Sciences, Barabanki, U.P. \\ ${ }^{3}$ Assistant Professor, Department of Pathology, Hind Institute of Medical Sciences, Barabanki, U.P. \\ ${ }^{4}$ Professor \& Head, Department of Obstetrics \& Gynaecology, Hind Institute of Medical Sciences, \\ Barabanki, U.P. \\ ${ }^{5}$ Professor, Department of Obstetrics \& Gynaecology, Hind Institute of Medical Sciences, \\ Barabanki, U.P. \\ ${ }^{6}$ Post-Graduate Resident, Department of Pathology, Hind Institute of Medical Sciences, Barabanki, U.P.
}

\begin{abstract}
Aims and Objective: (1)To record the colposcopic and cytological findings of the cases and to compare it with each other in detecting premalignant lesions of cervix taking histopathology as gold standard.(2)To correlate the findings of cytology and colposcopy with histopathology in detecting premalignant lesions of cervix.

Materials and Methods: This was a hospital based cross-sectional study conducted at HIMS,Barabanki.The study period was of one year.The study included pap smear samples, colposcopy reports and colposcopy guided cervical biopsy samples of 208 sexually active rural female patients of reproductive age group.

Results: Majority of the women were between 31-40 years(59.6\%).On PAP smear,ASC-US was found in 5.8\% of women, ASC-H in 1.4\% of women,LSIL in 6.7\% of women and HSIL in $6.2 \%$ of women.On colposcopy,LSIL was seen in $26.4 \%$ of women and HSIL in $17.8 \%$ of women. On histopathological examination, CIN I was seen in $16.8 \%$ of women followed by CIN II(8.2\%) and CIN III(5.8\%).Sensitivity and specificity of PAP smear was $29.7 \%$ and $94.4 \%$.Sensitivity and specificity of colposcopy was $85.9 \%$ and $74.3 \%$.

Conclusion: Pap smear had a poor sensitivity compared to colposcopy but a better specificity than colposcopy.Hence, it may be better to utilise both tests in screening of premalignant lesions of cervix as they complement each other.
\end{abstract}

Keywords: Premalignant Lesions of Cervix, Cytology, Colposcopy, Histopathology.

\section{Introduction}

Cancer cervix is the second most common cancer in women after carcinoma breast in the world, while it is the leading cancer in women in the developing countries including India. ${ }^{1}$ More than $80 \%$ patients present in a fairly advanced stage. ${ }^{2}$ According to the GLOBOCAN statistics, the estimated incidence of cervical cancer in the world is 528000 per year with 266000 annual deaths attributed to cervical cancer (approximately 50\%). ${ }^{3}$ India alone contributes to $23 \%$ of the total global cases annually. With an annual 67000 deaths, cervical cancer remains one of the major causes of cancer related mortality in India. ${ }^{4}$ Cervical intraepithelial neoplasia (CIN) is a premalignant condition of the uterine cervix.Detected in pre-malignant stages,cervical cancer is preventable and curable,so detection of premalignant lesions is very important.

\section{Aims And Objective}

The present study was conducted with aims and objectives to (1) to record the colposcopic and cytological findings of the cases and to compare it with each other in detecting premalignant lesions of cervix taking histopathology as gold standard; (2) to correlate the findings of cytology and colposcopy with histopathology in detecting premalignant lesions of cervix.

\section{Materials And Methods}

This was a hospital based cross-sectional study. The study was conducted in the Department of Pathology and Department of Obstetrics \& Gynaecology, Hind Institute of Medical Sciences, Safedabad, Barabanki, U.P. The study was performed after permission from Institutional Ethics Committee. The study period was of one year(2015-2016). The study included pap smear samples, colposcopy reports and colposcopy guided cervical biopsy samples of 208 sexually active rural female patients of reproductive age group, in and 
around Barabanki district (U.P) who came to the OPD of Gynaecology Department (HIMS, Barabanki,U.P.) with complaints of discharge per vagina / inter menstrual bleeding / post coital bleeding during the study period.

Samples of prepubertal and postmenopausal women who presented with gynaecological complaints, women with invasive carcinoma of cervix and other genital malignancies, pregnant and puerperial women, unmarried women and post hysterectomy cases were excluded from the study.

\section{Methods \\ PAP smear samples}

Pap smear samples of the female patients fulfilling the inclusion criteria were collected. Samples smeared on two glass slides (one slide with ectocervical material and a second slide with endocervical material) were received in the Pathology department in Coplin jar containing fixative- 95\% ethyl alcohol or equal parts of 95\% ethyl alcohol and ether. Pap smear was taken using Ayre's spatula after exposing cervix with Cusco's speculum. The prepared PAP smear slides were then stained according to the conventional PAP technique and examined under a compound light binocular microscope for cytological examination. The cytological interpretation of the smears was made according to the Bethesda System 2014 reporting criteria. ${ }^{5}$ The findings were recorded. All these female patients were also subjected to colposcopy and colposcopy guided cervical biopsy .

\section{Colposcopy reports}

Colposcopy reports of the female patients fulfilling the inclusion criteria of this study were collected from Gynaecology Department. For colposcopy examination, PRO MIS Colposcope -model COLPRO222DX (with zoom upto 40x) was used. Colposcopy diagnosis was made based on Modified Reid's Colposcopic Index. ${ }^{6,7}$ The findings were recorded. All these female patients underwent pap smear examination earlier and were also subjected to colposcopy guided cervical biopsy.

\section{Colposcopy guided cervical biopsy samples}

Colposcopy guided cervical biopsy samples of the female patients fulfilling the inclusion criteria of this study were collected.Biopsy specimens were received in the Pathology department in $10 \%$ formalin fixative solution.Cervical biopsy was taken from abnormal areas by punch-biopsy forceps under colposcopic guidance. The biopsied tissues were then subjected to detail gross examination.Routine tissue processing was done.Sections were cut and were stained with Haematoxylin and Eosin stain and mounted in DPX. The slides prepared were examined under a compound light binocular microscope for histopathological examination.Biopsy results were categorized according to CIN(Cervical intraepithelial neoplasia) and SIL(Squamous intraepithelial lesion) classification systems. ${ }^{8}$ The findings were recorded.The diagnosis of premalignant lesions of cervix was based on final histopathology report obtained. All these female patients underwent PAP smear examination and colposcopy examination before they were subjected to colposcopy guided cervical biopsies.

\section{Statistical analysis}

The descriptive statistics are presented .The results are presented in percentages. The Chi-square test was used to compare the categorical variables. The sensitivity, specificity, positive predictive value (PPV) and negative predictive value (NPV) were calculated for PAP smear and colposcopy taking histopathological finding as gold standard. The p-value $<0.05$ was considered significant. All the analysis was carried out on SPSS 16.0 version (Chicago, Inc., USA).

\section{Results}

Majority of the women were between $31-40$ years $(59.6 \%)$ followed by $41-50$ years $(31.2 \%)$ and $<30$ years $(9.1 \%)$ (Table-1). On PAP smear findings, ASC-US was found in $5.8 \%$ of the women and ASC-H was found in $1.4 \%$ of the women. LSIL was found in $6.7 \%$ of the women and HSIL was found in $6.2 \%$ of the women.NILM (Negative for intraepithelial lesion or malignancy) (79.3\%) was found to be in majority of the women. (Table-2).On colposcopy findings, LSIL was in $26.4 \%$ of the women and HSIL was in $17.8 \%$ of the women. Normal colposcopy was seen in $51.9 \%$ of the women. (Table-3). Histopathological finding of CIN I was seen in $16.8 \%$ of the women followed by CIN II (8.2\%) and \& CIN III (5.8\%). Chronic cervicitis/chronic cervicitis with squamous metaplasia was seen in majority of the women (52.9\%).Cervix was normal in $16.3 \%$ of women (Table-4).

With PAP smear finding of ASC-US which constitutes total 6 number of patients, correlation with histopathological findings was: $16.7 \%$ in CIN I category, $16.7 \%$ in CIN II category and 0 in CIN III category. With PAP smear finding of LSIL which constitutes total 14 number of patients,correlation with histopathological findings was: $35.7 \%$ in CIN I category, $14.3 \%$ in CIN II category and $7.1 \%$ in CIN III 
category. With PAP smear finding of ASC-H which constitutes total 3 number of patients,correlation with histopathological findings was: $33.3 \%$ in CIN I category, $33.3 \%$ in CIN II category and $33.3 \%$ in CIN III category.With PAP smear finding of HSIL which constitutes total 13 number of patients,correlation with histopathological findings was: $15.4 \%$ in CIN I category,30.8\% in CIN II category and $38.5 \%$ in CIN III category. PAP smear was significantly $(\mathrm{p}=0.0001)$ correlated with histopathological findings (Chi-square test). (Table-5).

With Reid's Colposcopy score 3-5(LSIL) which constitutes total 55 number of patients, correlation with histopathological findings was: $38.2 \% \%$ in CIN I category, $10.9 \%$ in CIN II category and $1.8 \%$ in CIN III category. With Reid's Colposcopy score 6-8(HSIL), which constitutes total 37 number of patients, correlation with histopathological findings was: $13.5 \%$ in CIN I category,29.7\% in CIN II category and $29.7 \%$ in CIN III category. Colposcopy finding was significantly $(\mathrm{p}=0.0001)$ correlated with histopathological finding $(\mathrm{Chi}$-square test). (Table-6).

With PAP smear finding of ASC-US which constitutes total 6 number of patients, correlation with colposcopy findings was: $16.7 \%$ in category of Reid's score 3-5(LSIL) and $16.7 \%$ in category of Reid's score 6-8(HSIL). With PAP smear finding of LSIL which constitutes total 14 number of patients,correlation with colposcopy findings was: $21.4 \%$ in category of Reid's score 3-5(LSIL) and $28.6 \%$ in category of Reid's score 6-8(HSIL). With PAP smear finding of ASC-H which constitutes total 3 number of patients,correlation with colposcopy findings was: $33.3 \%$ in category of Reid's score 3-5(LSIL) and 0 in category of Reid's score 6-8(HSIL). With PAP smear finding of HSIL which constitutes total 13 number of patients,correlation with colposcopy findings was: $23.1 \%$ in category of Reid's score 3-5(LSIL) and $15.4 \%$ in category of Reid's score 6-8(HSIL).PAP smear was insignificantly ( $\mathrm{p}>0.05$ ) correlated with colposcopy findings (Chi-square test).

(Table-7).

The sensitivity and specificity of PAP smear was $29.7 \%$ and $94.4 \%$ respectively. Accuracy of PAP smear was 74.5\%.(Table-8). The sensitivity and specificity of Colposcopy was $85.9 \%$ and $74.3 \%$ respectively. Accuracy of colposcopy was $77.9 \%$ (Table-9).

Table-1: Distribution of women according to age

\begin{tabular}{|l|c|c|}
\hline Age in years & $\begin{array}{c}\text { No. } \\
(\mathbf{n = 2 0 8})\end{array}$ & \% \\
\hline$<30$ & 19 & 9.1 \\
\hline $31-40$ & 124 & 59.6 \\
\hline $41-50$ & 65 & 31.2 \\
\hline
\end{tabular}

Table-2: Distribution of women according to PAP smear findings

\begin{tabular}{|l|c|c|}
\hline \multicolumn{1}{|c|}{ PAP smear findings } & $\begin{array}{c}\text { No. } \\
(\mathbf{n = 2 0 8})\end{array}$ & \% \\
\hline NILM & 165 & 79.3 \\
\hline ASC-US & 6 & 5.8 \\
\hline LSIL & 14 & 6.7 \\
\hline ASC-H & 3 & 1.4 \\
\hline HSIL & 13 & 6.2 \\
\hline Unsatisfactory smear & 7 & 3.4 \\
\hline
\end{tabular}

Table-3: Distribution of women according to Colposcopy findings

\begin{tabular}{|l|c|c|}
\hline Colposcopy findings( REID'S SCORE) & $\begin{array}{c}\text { No. } \\
(\mathbf{n = 2 0 8})\end{array}$ & \% \\
\hline Score 0-2 (Normal colposcopy) & 108 & 51.9 \\
\hline Score 3-5(LSIL) & 55 & 26.4 \\
\hline Score 6-8(HSIL) & 37 & 17.8 \\
\hline Unsatisfactory Colposcopy & 8 & 3.8 \\
\hline
\end{tabular}

Table-4: Distribution of women according to Histopathology findings

\begin{tabular}{|l|c|c|}
\hline Histopathology findings & $\begin{array}{c}\text { No. } \\
(\mathbf{n = 2 0 8})\end{array}$ & \% \\
\hline Normal & 34 & 16.3 \\
\hline $\begin{array}{l}\text { Chronic cervicitis /chronic cervicitis with } \\
\text { metaplasia }\end{array}$ & 110 & 52.9 \\
\hline CIN I & 35 & 16.8 \\
\hline CIN II & 17 & 8.2 \\
\hline CIN III & 12 & 5.8 \\
\hline
\end{tabular}


Comparison and Correlation of Cytology, Colposcopy and Histopathology of Premalignant...

Table-5: Correlation of PAP smear with histopathological findings

\begin{tabular}{|c|c|c|c|c|c|c|c|c|c|c|c|}
\hline \multirow{3}{*}{$\begin{array}{c}\text { PAP } \\
\text { Smear }\end{array}$} & \multirow[t]{3}{*}{ Total } & \multicolumn{10}{|c|}{ Histopathological findings } \\
\hline & & \multicolumn{2}{|c|}{ Normal } & \multicolumn{2}{|c|}{$\begin{array}{l}\text { Chronic cervicitis/ } \\
\text { chronic cervicitis } \\
\text { with metaplasia }\end{array}$} & \multicolumn{2}{|c|}{ CIN I } & \multicolumn{2}{|c|}{ CIN II } & \multicolumn{2}{|c|}{ CIN III } \\
\hline & & No. & $\%$ & No. & $\%$ & No. & $\%$ & No. & $\%$ & No. & $\%$ \\
\hline NILM & 165 & 31 & 18.8 & 97 & 58.8 & 25 & 15.1 & 8 & 25.8 & 4 & 2.4 \\
\hline ASC-US & 6 & 1 & 16.7 & 3 & 50 & 1 & 16.7 & 1 & 16.7 & 0 & 0 \\
\hline LSIL & 14 & 0 & 0 & 6 & 42.8 & 5 & 35.7 & 2 & 14.3 & 1 & 7.1 \\
\hline ASC-H & 3 & 0 & 0 & 0 & 0.0 & 1 & 33.3 & 1 & 33.3 & 1 & 33.3 \\
\hline HSIL & 13 & 0 & 0 & 2 & 15.4 & 2 & 15.4 & 4 & 30.8 & 5 & 38.5 \\
\hline $\begin{array}{l}\text { Unsatisfactory } \\
\text { smear }\end{array}$ & 7 & 2 & 57.1 & 2 & 28.6 & 1 & 14.3 & 1 & 14.3 & 1 & 14.3 \\
\hline Total & 208 & 34 & 16.3 & 110 & 52.9 & 35 & 16.8 & 17 & 8.2 & 12 & 5.8 \\
\hline
\end{tabular}

$\mathrm{p}=0.0001$ (Chi-square test)

Table-6: Correlation of Reid's Colposcopy score with histopathological findings

\begin{tabular}{|c|c|c|c|c|c|c|c|c|c|c|c|}
\hline \multirow[t]{3}{*}{ Reid's score } & \multirow[t]{3}{*}{ Total } & \multicolumn{10}{|c|}{ Histopathological findings } \\
\hline & & \multicolumn{2}{|c|}{ Normal } & \multicolumn{2}{|c|}{$\begin{array}{l}\text { Chronic } \\
\text { cervicitis/ } \\
\text { Chronic } \\
\text { cervicitis with } \\
\text { metaplasia } \\
\end{array}$} & \multicolumn{2}{|c|}{ CIN I } & \multicolumn{2}{|c|}{ CIN II } & \multicolumn{2}{|c|}{ CIN III } \\
\hline & & No. & $\%$ & No. & $\%$ & No. & $\%$ & No. & $\%$ & No. & $\%$ \\
\hline $\begin{array}{l}\text { Normal (REID'S } \\
\text { SCORE-0-2) }\end{array}$ & 108 & 24 & 22.2 & 75 & 69.4 & 9 & 8.3 & 0 & 0 & 0 & 0 \\
\hline $\begin{array}{l}\text { LSIL (REID'S } \\
\text { SORE-3-5) }\end{array}$ & 55 & 5 & 9.1 & 22 & 40 & 21 & 38.2 & 6 & 10.9 & 1 & 1.8 \\
\hline $\begin{array}{l}\text { HSIL (REID'S } \\
\text { SCORE-6-8) }\end{array}$ & 37 & 2 & 5.4 & 8 & 21.7 & 5 & 13.5 & 11 & 29.7 & 11 & 29.7 \\
\hline $\begin{array}{l}\text { Unsatisfactory } \\
\text { colposcopy }\end{array}$ & 08 & 3 & 37.5 & 5 & 62.5 & 0 & 0 & 0 & 0 & 0 & 0 \\
\hline Total & 208 & 34 & 16.3 & 110 & 52.9 & 35 & 16.8 & 17 & 8.2 & 12 & 5.8 \\
\hline
\end{tabular}

$\mathrm{p}=0.0001$ (Chi-square test)

Table-7: Correlation of PAP smear with colposcopy findings

\begin{tabular}{|c|c|c|c|c|c|c|c|c|c|}
\hline \multirow{3}{*}{ PAP smear } & \multirow[t]{3}{*}{ Total } & \multicolumn{6}{|c|}{ Colposcopy findings } & & \\
\hline & & \multicolumn{2}{|c|}{$\begin{array}{c}\text { Normal } \\
\text { (REID'S } \\
\text { SCORE- } \\
\quad 0-2)\end{array}$} & \multicolumn{2}{|c|}{$\begin{array}{c}\text { LSIL (REID'S } \\
\text { SORE- } \\
\text { 3-5) }\end{array}$} & \multicolumn{2}{|c|}{$\begin{array}{c}\text { HSIL (REID'S } \\
\text { SCORE- } \\
6-8)\end{array}$} & \multicolumn{2}{|c|}{$\begin{array}{l}\text { Unsatisfactory } \\
\text { colposcopy }\end{array}$} \\
\hline & & No. & $\%$ & No. & $\%$ & No. & $\%$ & No & $\%$ \\
\hline NILM & 165 & 86 & 52.1 & 46 & 27.9 & 29 & 17.6 & 4 & 2.4 \\
\hline ASC-US & 6 & 4 & 66.7 & 1 & 16.7 & 1 & 16.7 & 0 & 0 \\
\hline LSIL & 14 & 7 & 50 & 3 & 21.4 & 4 & 28.6 & 0 & 0 \\
\hline ASC-H & 3 & 2 & 66.7 & 1 & 33.3 & 0 & 0 & 0 & 0 \\
\hline HSIL & 13 & 6 & 46.15 & 3 & 23.1 & 2 & 15.4 & 2 & 15.4 \\
\hline $\begin{array}{l}\text { Unsatisfactory } \\
\text { smear }\end{array}$ & 7 & 3 & 42.8 & 1 & 14.3 & 1 & 14.3 & 2 & 28.6 \\
\hline Total & 208 & 108 & 51.9 & 55 & 26.4 & 37 & 17.8 & 8 & 3.8 \\
\hline
\end{tabular}

$\mathrm{p}=0.11$ (Chi-square test)

Table-8: Diagnostic efficacy of PAP smear test

\begin{tabular}{|c|c|c|c|}
\hline & Histopathology & & Total \\
\hline PAP smear & Positive & Negative & 27 \\
\hline Positive & 19 & 8 & 181 \\
\hline Negative & 45 & 136 & 208 \\
\hline Total & 64 & & \\
\hline Sensitivity & $29.7 \%$ & & \\
\hline Specificity & $94.4 \%$ & & \\
\hline PPV & $70.4 \%$ & & \\
\hline NPV & $75.1 \%$ & & \\
\hline Accuracy & $74.5 \%$ & & \\
\hline
\end{tabular}


Comparison and Correlation of Cytology, Colposcopy and Histopathology of Premalignant...

Table-9: Diagnostic efficacy of Colposcopy test

\begin{tabular}{|l|c|c|c|}
\hline & \multicolumn{2}{|c|}{ Histopathology } & Total \\
\hline Colposcopy & \multicolumn{1}{|c|}{ Positive } & Negative & 92 \\
\hline Positive & 55 & 37 & 116 \\
\hline Negative & \multicolumn{1}{|c|}{64} & 107 & 208 \\
\hline Total & \multicolumn{3}{|}{} \\
\hline Sensitivity & $85.9 \%$ & 144 & \\
\hline Specificity & $74.3 \%$ & \\
\hline PPV & $59.8 \%$ & \\
\hline NPV & $92.2 \%$ & \\
\hline Accuracy & $77.9 \%$ \\
\hline
\end{tabular}

\section{Discussion}

Cervical intraepithelial neoplasia (CIN) is a premalignant lesion that may exist at any one of three stages: CIN1, CIN2, or CIN3.If left untreated, CIN2 or CIN3 (collectively referred to as CIN2+) can progress to cervical cancer. It is estimated that approximately $1-2 \%$ of women have CIN2+ each year., ${ }^{9}, 10,11$

The present study included pap smear samples, colposcopy reports and colposcopy guided cervical biopsy samples of 208 sexually active rural female patients of reproductive age group. In the present study, majority of the women were between $31-40(59.6 \%)$ years followed by $41-50(31.2 \%)$ and $<30(9.1 \%)$ years.

In the present study, on PAP smear, ASC-US was found in 5.8\% of the women and ASC-H was found in $1.4 \%$ of the women .LSIL was found in $6.7 \%$ of the women and HSIL was found in $6.2 \%$ of the women. NILM (79.3\%) was found to be in majority of the women. Similar findings were seen in previous studies done by Ashmita et al $(2013)^{12}$, Chaudhary et al $(2014)^{13}$, Joshi et al $(2015)^{14}$ and various others.

In the present study, on colposcopy findings, LSIL was in $26.4 \%$ of the women and HSIL was in $17.8 \%$ of the women. Unsatisfactory colposcopy was in $3.8 \%$ of the women. Normal colposcopy was seen in $51.9 \%$ of the women. Similar findings were seen in previous studies done by Ashmita et al (2013) ${ }^{12}$, Chaudhary et al (2014) ${ }^{13}$,Joshi et al (2015) ${ }^{14}$, Krishnegowda and Veena (2014) $)^{15}$ and various others.

In the present study, histopathological finding of chronic cervicitis/chronic cervicitis with squamous metaplasia was seen in majority of the women $(52.9 \%)$. CIN I was seen in $16.8 \%$ of the women followed by CIN II (8.2\%) and \& CIN III (5.8\%). Normal cervix was seen in $16.3 \%$ of women. Similar findings were seen in previous studies done by Joshi et al (2015) ${ }^{14}$, Gopal et al (2013) ${ }^{16}$, Chaudhary et al (2014) $)^{13}$, Bodal and Brar $(2014)^{17}$ and various others.

In the present study, PAP smear findings were significantly $(\mathrm{p}=0.0001)$ correlated with histopathological findings . This finding is similar to the results of the study done by Nayani and Hendre $(2015)^{18}$, Bukhari et al (2012) $)^{19}$, Ashmita et al $(2013)^{12}$ and various others.

In the present study, colposcopy findings were significantly $(\mathrm{p}=0.0001)$ correlated with histopathological findings.This finding is similar to the results of the study done by Nayani and Hendre $(2015)^{18}$, Bukhari et al $(2012)^{19}$, Ashmita et al $(2013)^{12}$ and various others.

In the present study, PAP smear findings were insignificantly $(p>0.05)$ correlated with coposcopy findings.This finding is similar to the results of the study done by Nayani and Hendre $(2015)^{18}$, Bukhari et al $(2012)^{19}$, Ashmita et al $(2013)^{12}$ and various others.

In the present study, the sensitivity of PAP smear was $29.7 \%$, specificity was $94.4 \%$, PPV was $70.4 \%$, NPV was $75.1 \%$ and accuracy was $74.5 \%$ for diagnosing premalignant lesions of cervix. The accuracy of pap smear in our study was $74.5 \%$ which is comparable to the findings of the studies of Chaudhary et al $(2014)^{13}$ $(76 \%)$, Bhatla et al $(2007)^{20}(89 \%)$, Maziah et al $(1991)^{21}(90 \%)$, Jain et al $(2010)^{22}(73.2 \%)$, Saha et al $(2005)^{23}$ $(79.1 \%)$, Naik et al $(2015)^{24}(74.5 \%)$. However, Mallur et al $(2009)^{25}$ and Ashmita et al (2013) ${ }^{12}$ concluded the accuracy of PAP smear to be $40 \%$ and $33.96 \%$

In the present study, the sensitivity of Colposcopy was $85.9 \%$,specificity was $74.3 \%$, PPV was $59.8 \%$, NPV was $92.2 \%$ and accuracy was $77.9 \%$ for diagnosing premalignant lesions of cervix. The accuracy of colposcopy in this study was $77.9 \%$ which is in parallel to the findings of the studies of Maziah et al(1991 $)^{21}$ $(94 \%)$, Ashmita et al $(2013)^{12}(86.54 \%)$, Mallur et al $(2009)^{25}(80 \%)$, Chaudhary et al $(2014)^{13}(80.50 \%)$ and Boicea et al $(2012)^{26}(98.3 \%)$.

Literature is replete with data pertaining to the sensitivity of Pap smear and colposcopy ranging from $27 \%$ to $50 \%$ vs $44 \%-89 \%$ respectively. Specificity of Pap smear and colposcopy ranging from $19.5 \%-98.71 \%$ vs 52\%-93.4\% respectively. ${ }^{12,13,25,27,28}$ In the present study,overall Pap smear had a poor sensitivity compared to colposcopy, $29.7 \%$ vs $85.9 \%$ respectively. Pap smear had a better specificity though not significantly compared to colposcopy, $94.4 \%$ vs $74.3 \%$ respectively.

The incidence of premalignant lesions of cervix in our study was $30.8 \%$. The incidence of premalignant lesions of cervix in various studies range from $8.15 \%$ to $35.2 \%{ }^{12,13,25,27,29,30}$

The main goal of cervical screening is to identify women with premalignant lesions of cervix which are precursors of invasive cancer and require treatment, thus ultimately decreasing morbidity and mortality due 
to cervical cancer. The results from the current study support the claim to perform combination screening tests as part of routine screening for cervical cancer screening rather than pap smear alone in order to detect maximum number of cases with accuracy and minimal loss of patients to follow up.

\section{Conclusion}

Pap smear had a poor sensitivity compared to colposcopy. Pap smear had a better specificity though not significantly compared to colposcopy. Hence, it may be better to utilise both tests in screening of premalignant lesions of cervix as they complement each other.

\section{References}

[1]. Park's Textbook of Social \& Preventive Medicine, $20^{\text {th }}$ Ed, 2007: page-337

[2]. Shrivastava S, Mahantshetty U, Engineer R, Tongaonkar H, Kulkarni J, et al. (2013) Treatment and outcome in cancer cervix patients treated between 1979 and 1994: a single institutional experience. J Cancer Res Ther 9: 672-679.

[3]. Ferlay J SI, Ervik M, Dikshit R, Eser S, Mathers C, et al. (2013) Cancer Incidence and Mortality Worldwide: IARC CancerBase No. 11 [Internet]. Lyon, France: International Agency for Research on Cancer: 2012.

[4]. Nandakumar A, Ramnath T, Chaturvedi M. The magnitude of cancer cervix in India. Indian J Med Res. 2009;130(3):219-221

[5]. Nayar R,Wilbur DC,eds. The Bethesda System for Reporting Cervical Cytology. Definitions, Criteria and Explanatory Notes. $3^{\text {rd }}$ ed. Springer;2015.

[6]. Reid R, Scalzi P. (1985) Genital warts and cervical cancer. VII. An improved colposcopic index for differentiating benign papillomaviral infections from high-grade cervical intraepithelial neoplasia. Am J Obstet Gynecol; 153:611-618

[7]. Sellors JW, Sankaranarayanan R (2003). Colposcopy and Treatment on Cervical Intraepithelial Neoplasia : A Beginners' Manual. IARCPress, Lyon, France.

[8]. IARC (International agency for research on cancer,WHO) Handbooks of Cancer Prevention Volume 10: Cervix cancer screening.

[9]. Arbyn $\mathrm{M}$ et al. Evidence regarding human papillomavirus testing in secondary prevention of cervical cancer. Vaccine , 2012, 30 Suppl 5: F88-99.

[10]. Joshi S et al. Screening of cervical neoplasia in HIV-infected women in India. AIDS, 2013, 27(4):607-615

[11]. Zhang HY et al. HPV prevalence and cervical intraepithelial neoplasia among HIV-infected women in Yunnan Province, China: a pilot study. Asian Pacific Journal of Cancer Prevention, 2012, 13(1):91-96.

[12]. Ashmita.D, Shakuntala.P.N, Shubha.R.Rao, S.K.Sharma, Geethanjali.S. Comparison and Correlation of PAP Smear, Colposcopy and Histopathology in Symptomatic Women and Suspicious Looking Cervix in a Tertiary Hospital Care Centre. International Journal of Health Sciences \& Research, 2013; 50 (5).

[13]. Chaudhary RD, Inamdar SA, Hariharan C. Correlation of diagnostic efficacy of unhealthy cervix by cytology, colposcopy and histopathology in women of rural areas. Int J Reprod Contracept Obstet Gynecol. 2014; 3(1): 213-218.

[14]. Joshi Chandrakala, Kujur Pratima, Thakur Nitya. Correlation of Pap Smear and Colposcopy in Relation to Histopathological Findings in Detection of Premalignant Lesions of Cervix in A Tertiary Care Centre. International Journal of Scientific Study 2015; $3(8)$

[15]. Krishnegowda S, Veena MS. Efficacy of coiposcopy technique with Pap smear and histology in screening of cervical lesions. Int J Repord Contracept Obstet Gynecol 2014;3:696-702.

[16]. N. Gopal, Prashant. S. Joshi, Ravindra Pukale, Shamashoor. "Colposcopic findings in Unhealthy Cervix and its comparison with Cytology and Histopathology". Journal of Evolution of Medical and Dental Sciences 2013; Vol2, Issue 26, July 1; Page: 46634671 .

[17]. Bodal VK, Brar BK. Correlation of pap smear with histopathological findings in malignant and non-malignant lesions of cervix. Glob J Med Res E Gynecol Obstet 2014;14:19-23.

[18]. Nayani ZS, Hendre PC. Comparison and correlation of Pap smear with colposcopy and histopathology in evaluation of cervix. J Evol Med Dent Sci 2015;4(53):9236-9247

[19]. Bukhari MH, Saba K, Qamar S, Majeed MM, Niazi S, Naeem S. Clinicopathological importance of Papanicolaou smears for the diagnosis of premalignant and malignant lesions of the cervix. J Cytol 2012;29:20-5

[20]. Bhatla N,Mukhopadhyay A,Kriplani A,Pandey RM,Gravitt EP,Shah KV,et al.Evaluation of adjunctive tests for cervical cancer screening in low resource settings.Indian J Cancer 2007;44:51-5.

[21]. Maziah AM, Sharifah NA, Yahya A. Comparative study of cytologic and colposcopic findings in preclinical cervical cancer. Malays J Pathol 1991;13(2):105-8

[22]. Jain V, Vyas AS. Cervical Neoplasia-Cyto-Histological Correlation (Bethesda System) A Study of 276 Cases. J Cytol Histol 2010;1:106.

[23]. Saha R, Thapa M. Correlation of cervical cytology with cervical histology. Kathmandu Univ Med J (KUMJ). 2005;3:222-4

[24]. Naik R, Minj MM, Panda R, Satpathi S, Behera PK, Panda KM. Cytohistological correlation and accuracy of the pap smear test in diagnosis of cervical lesions: a hospital based cross-sectional study from Odisha, India. Medical Science. 2015;3:242-9 .

[25]. Mallur PR, Desai BR, Anita D, Geeta D, Bhavana S, Pallav G. Sequential Screening with Cytology and Colposcopy in Detection of Cervical Neoplasia. J. South Asian Feder Obst Gynae 2009;1(3):45-8.

[26]. Boicea A, Patrascu A, Surlin V, Iliescu D, Schenker M, Chiutu L. Correlations between colposcopy and histologic results from colposcopically directed biopsy in cervical precancerous lesions. Rom J Morphol Embryol 2012;53(3 Suppl):735-41.

[27]. Bhalerao A, Kulkarni S, Ghike S, Kawthalkar A, Joshi S. Correlation of pap smear, colposcopy and histopathology in women with unhealthy cervix. J South Asian Feder Obst Gynae 2012;4(2):97-8.

[28]. Steward ML, Yvonne C. Collins. (2003)Strength of correlations between colposcopic impression and biopsy histology. Gynaecologic Oncology; 89:424-428.

[29]. Nieminem. P, Vuorma. S, Vikki, M, Hakama. M, Anttila. A.( 2004) Comparision of HPV test versus conventional and automationassisted Pap screening as potential screening tools for preventing cervical cancer. RCOG 2004, BJOG: An Intern. J. Obstet Gynaecol, Aug ; III:842-848.

[30]. Seckin NC, Turhan NO, et al. (1997). Routine colposcopic evaluation of patients with persistent inflammatory cellular changes on Pap smear. Int J Gynaecol Obstet;59:25-29. 